\title{
Quantitative detection of free 24S-hydroxycholesterol, and 27-hydroxycholesterol from human serum
}

\author{
Veera Venkata Ratnam Bandaru ${ }^{1 *}$ and Norman J Haughey ${ }^{1,2^{*}}$
}

\begin{abstract}
Background: Cholesterol metabolism is important for the maintenance of myelin and neuronal membranes in the central nervous system. Blood concentrations of the brain specific cholesterol metabolite 24S-hydroxysterol to the peripheral metabolite 27-hydroxycholesterol may be useful surrogate markers for neurodegenerative diseases including Alzheimer's disease, Huntington's disease, HIV-Associated Neurocognitive Disorders, and Multiple Sclerosis. However, current methods to isolate hydroxycholesterols are labor intensive, prone to produce variable extraction efficiencies and do not discriminate between free and esterfied forms of hydroxycholesterols. Since free hydroxycholesterols are the biologically active form of these sterols, separating free from esterfied forms may provide a sensitive measure to identify disease-associated differences in brain sterol metabolism.
\end{abstract}

Results: We found that average human serum concentrations were $12.3 \pm 4.79 \mathrm{ng} / \mathrm{ml}$ for free 24(s)-hydroxycholesterol and $17.7 \pm 8.5 \mathrm{ng} / \mathrm{ml}$ for 27-hydroxycholesterol.

Conclusion: Serum measurements of these biologically active oxysterols may be useful surrogate measures for brain health in a variety of neurodegenerative conditions.

Keywords: Alzheimer's, Multiple sclerosis, HIV associated neurocogntiive disorder, Serum, 24S-hydroxycholesterol, 27-hydroxycholesterol, LC/ESI/MS/MS

\section{Background}

Hydroxycholesterols are mono-oxygenated derivatives of cholesterol (cholesten-5-3/-ol) that comprise a family of polycyclic compounds that contain a second oxygen atom as a hydroxyl group on the skeleton of cholesterol. In vivo, hydroxycholesterols are present as unesterified (biologically active) and esterified forms (largely biologically inert) [1] Hydroxycholesterols are formed through enzymatic conversion of cholesterol or by free radical autoxidation, and exhibit a short half life relative to cholesterol. Hydroxycholesterols are important intermediates in a number of catabolic pathways that regulate a variety of

\footnotetext{
*Correspondence: vbandar2@jhmi.edu; nhaughe1@jhmi.edu

'Department of Neurology, Richard T. Johnson Division of

Neuroimmunology and Neurological Infections, The Johns Hopkins University School of Medicine, Carnegie 616A, 600 North Wolfe Street, Baltimore 21287, MD, USA

2Department of Psychiatry, Division of Geriatric Psychiatry and

Neuropsychiatry, The Johns Hopkins University School of Medicine, Baltimore, MD, USA
}

biological effects. For example, hydroxycholesterols are important for cholesterol transport from the periphery to the liver [2], modulate the expression of sterol sensitive genes involved in lipid and sterol biosynthesis [3,4], act as substrates for the formation of bile salts [5], serve as ligands that activate nuclear liver $\mathrm{X}$ receptors$\alpha$ and $-\beta[6]$, and are involved in the regulation of cholesterol and lipid metabolism and homeostasis [7,8]. In the central nervous system, hydroxycholesterols regulate arachidonic acid release, voltage-gated calcium channels, synaptic plasticity, induce IL-8, promote neurogenesis and induce apoptosis [9-16]. Consistent with these important roles for regulating biological functions, levels of free hydroxycholesterols are extremely low and tightly controlled, with the majority of hydroxycholesterols maintained in esterified forms $[17,18]$.

Many cell types have the ability to oxygenate cholesterol by mechanisms that involve the cytochrome P450 family of oxidases (CYP). Cell type specific expression CYP subtypes results in the tissue-specific production of particular 
oxysterol species. Several CYP are present in the central nervous system including 24S-hydroxycholesterolhydroxylase (CYP46), a P450 family member that is expressed in neurons, glia and in endothelial cells of the blood-brain barrier [19]. 24S-hydroxycholesterol (Cholest-5-en-3 $3,24(S)$ diol) is the most abundant hydroxycholesterol in brain and is the primary transport form of cholesterol from the central nervous system into the blood, with smaller amounts eliminated through cerebrospinal fluid [20]. It has been suggested by several studies that serum or plasma levels of $24 S$-hydroxycholesterol may reflect brain developmental and neuropathological changes associated with Alzheimer's disease (AD), Huntington's disease and Multiple Sclerosis [21-27]. 24S-hydroxycholesterol is often expressed as a ratio to 27 -hydroxycholesterol (25R-Cholest5-en-3 $\beta, 26$-diol). 27-hydroxycholesterol is formed primarily in the periphery by the P450 enzyme sterol 27-hydroxylase (CYP27) [24]. CYP27 is expressed in arterial endothelium, macrophages and to lesser extents in other tissues such as cortex, spleen, liver, kidney, adrenal gland and heart [28,29]. 27-hydroxycholesterol can function as a ligand for nuclear receptors, liver X receptors (LXR) and farnesoid $\mathrm{X}$-activated receptors (FXRs) [30]. 27-hydroxycholesterol can also regulate hydrocymethylglutaryl-CoA reductase [31,32], and enhances cholesterol efflux from the vascular endothelium [33]. Macrophages have the highest capacity to convert cholesterol to 27-hydroxycholesterol, which is then transported in blood to the liver where it is converted to bile acids [34].

Hydroxycholesterol detection and quantification has been accomplished in a variety of tissues by isotope-dilution gas- chromatography-mass spectrometry (GC-MS) [18,35], gasand high-performance liquid chromatography (HPLC)/mass spectrometry [36], HPLC with UV detection of cholesterol oxidation products in tissues [37], as $\Delta 4$ - 3-ketone derivatives by HPLC [38] and as derivatives of GP hydrazones [39]. Because "free" hydroxycholesterol levels are below the detection limits of many instruments, saponification and/or solid phase extraction techniques have typically been used to extract "total" hydroxycholesterols. The primary advantage of these methods is a high yield of hydroxycholesterols. The disadvantages include lengthy sample preparation times, sample loss, inconsistent yields, and the inability to discriminate between free and esterified hydroxycholesterols. In this study we developed a simple and direct extraction protocol and sensitive LC/ESI/MS/MS method for separation and simultaneous quantitative determination of free $24 \mathrm{~S}$ hydroxycholesterol and 27-hydroxycholesterol in serum.

\section{Results}

Identification and Optimization of ESI/MS/MS for 24S-hydroxycholesterol and 27-hydroxycholesterol

The structures of cholesterol, 24S-hydroxycholesterol, 27hydroxycholesterol and 24(RS)-hydroxycholesterol (d6) are shown in Figure 1. Hydroxycholesterols were identified -as ammonium adducts of 24S-hydroxycholesterol and 27hydroxycholesterol or 24(R/S)-hydroxycholesterol (d6) (dissolved in pure $\mathrm{CH} 3 \mathrm{OH}$ with $5 \mathrm{mM} \mathrm{HCOONH4)} \mathrm{using}$ ESI/MS operated in the positive ion mode. Molecules of 24S-hydroxycholesterol and 27-hydroxycholesterol were detected as ammonium adducts $[\mathrm{M}+\mathrm{NH} 4]$ with a molecular weight of $420.3 \mathrm{~m} / \mathrm{z}$ (Figure $2 \mathrm{~A}$ ). The collision induced

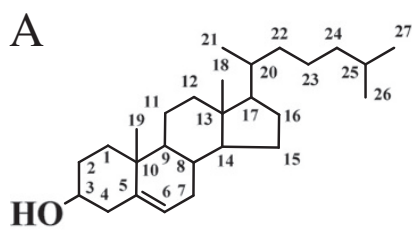

Cholesterol (cholest-5-en-3 $\beta$-ol)
B<smiles>CC(C)C(O)CCC(C)C1CCC2C3CC=C4CC(O)CCC4(C)C3CCC12C</smiles>

24S-hydroxycholesterol

3b (cholest-5-en-3b, 24(S)-diol)

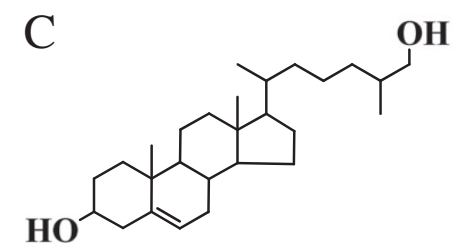<smiles>CC(CCC(O)C(C)(C)C)C1CCC2C3CC=C4CC(O)CCC4(C)C3CCC12C</smiles>

27-hydroxycholesterol (cholest-5-en-3 $\beta, 27$-diol)

24(R/S)-hydroxycholesterol (d6)

Figure 1 Structural representation of cholesterol and related products. Structures of A) Cholesterol, B) 24S-hydroxycholesterol, C) 27-hydroxycholesterol and D) 24-(R/S)-hydroxycholesterol (d6). 


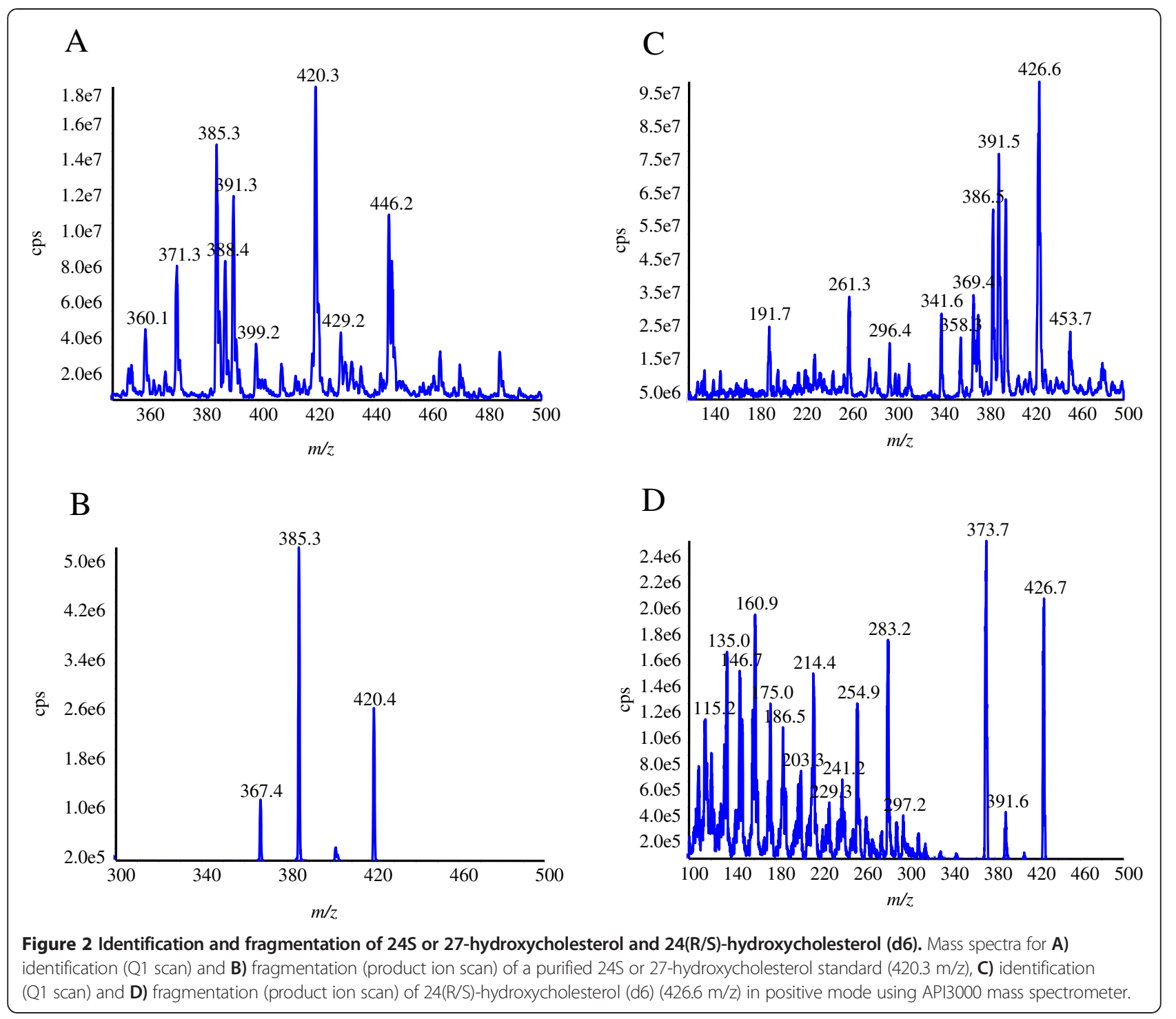

dissociation of individual hydroxycholesterol species were then characterized by product ion scanning using the highest abundance product ions with adequate signal/noise ratios. For 24S-hydroxycholesterol and 27-hydroxycholesterol the molecular fragment identified was $385.3 \mathrm{~m} / \mathrm{z}$ (Figure 2B). For 24 (R/S) hydroxycholesterol (d6) the molecular ion identified was $426.6 \mathrm{~m} / \mathrm{z}$ and the highly abundant product was $373.7 \mathrm{~m} / \mathrm{z}$ (Figure 2C,D). We optimized the following mass spectrometer parameters that were then used for all hydroxycholesterol species: Ion spray voltage (IS) $2500 \mathrm{eV}$, temperature (TEM) $250^{\circ} \mathrm{C}$, nebulizer gas (NEB) 13 psi, curtain gas (CUR) 8 psi, collision activated dissociation (CAD) $12 \mathrm{psi}$, dwell time (DW) $150 \mathrm{msec}$, and entrance potential (EP) $10 \mathrm{eV}$. The declustering potential (DP), focusing potential (FP), collision energy (CE), collision exit potential (CXP), orientation of the electrospray needle and auxiliary gas flow were individually optimized for each analyte by both direct infusion and flow thorough infusion
(FIA) to maximize accuracy and sensitivity (Table 1 ). We developed our method with two fragmented ions of $24(\mathrm{R} / \mathrm{S})$ hydroxycholesterol (d6) (426.6/373.7 \& 426.7/391.6), and ultimately chose to use $426.6 / 373.7$, as this transition displayed a high signal/noise ratio, a stable low baseline, was abundant, and stable compared to the 426.7/391.6 transition, which showed an unstable baseline (see in Figure 2D).

\section{Optimization of HPLC conditions for separation of hydroxycholesterols}

Hydroxycholesterols were separated by HPLC using a C18 column. The HPLC gradient conditions were optimized to obtain good separation between 24S-hydroxycholesterol and 27-hydroxycholesterol with a short running time ( $12 \mathrm{~min}$ ). The best signal to noise separation was observed using pure $\mathrm{CH} 3 \mathrm{OH}$ containing $5 \mathrm{mM}$ HCOONH 4 as a linear mobile phase. The elution sequence for 24S-hydroxycholesterol, 27-hydroxycholesterol and the 
Table 1 Molecular and fragment ion $\mathrm{m} / \mathrm{z}$, and associated parameters for detection and quantification of 24S-hydroxycholesterol, 27-hydroxycholesterol and 24(R/S) hydroxycholesterol (d6) individual species by MRM

\begin{tabular}{llllllllll}
\hline Anylate & Mol. Wt. & Molecular ion & Fragment ion & Time & DP* & FP* & Dwell* & CE* & CXP* $^{*}$ \\
\hline 24S-hydroxycholesterol & 402.66 & 420.3 & 385.5 & 10.48 & 60 & 400 & 150 & 13 & 5 \\
27-hydroxycholesterol & 402.66 & 420.3 & 385.5 & 10.83 & 60 & 400 & 150 & 13 & 5 \\
24(R/S) hydroxycholesterol (d6) & 408.69 & 426.4 & 373.6 & 10.47 & 45 & 250 & 150 & 20 & 10 \\
\hline
\end{tabular}

${ }^{*} \mathrm{DP}=$ Declustereing potential $(\mathrm{eV}), \mathrm{FP}=$ focusing potential $(\mathrm{eV})$, Dwell = Dwell time (ms), $\mathrm{CE}=$ Collision energy $(\mathrm{eV}), \mathrm{CXP}=\mathrm{Collision}$ exit potential $(\mathrm{eV})$.

internal standard 24(R/S)-hydroxycholesterol (d6) were identified using reference standards (Figure 3 ). The retention times were $10.45 \mathrm{~min}$ for 24S-hydroxycholesterol, $10.83 \mathrm{~min}$ for 27 -hydroxycholesterol, and $10.48 \mathrm{~min}$ for 24 (R/S)-hydroxycholesterol (Figure 3A,B).

\section{Recovery, accuracy and precision}

Intra-day and inter-day accuracy and precision were evaluated by spiking known amounts of 24-hydroxycheolsterol, and 27-hydroxycheolsterol $(50 \mathrm{ng} / \mathrm{ml})$ in serum $(\mathrm{n}=5)$. The peak area for 24S-hydroxycholesterol and
A

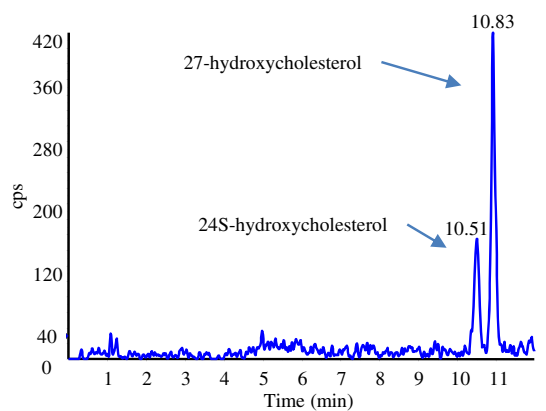

$\mathrm{C}$
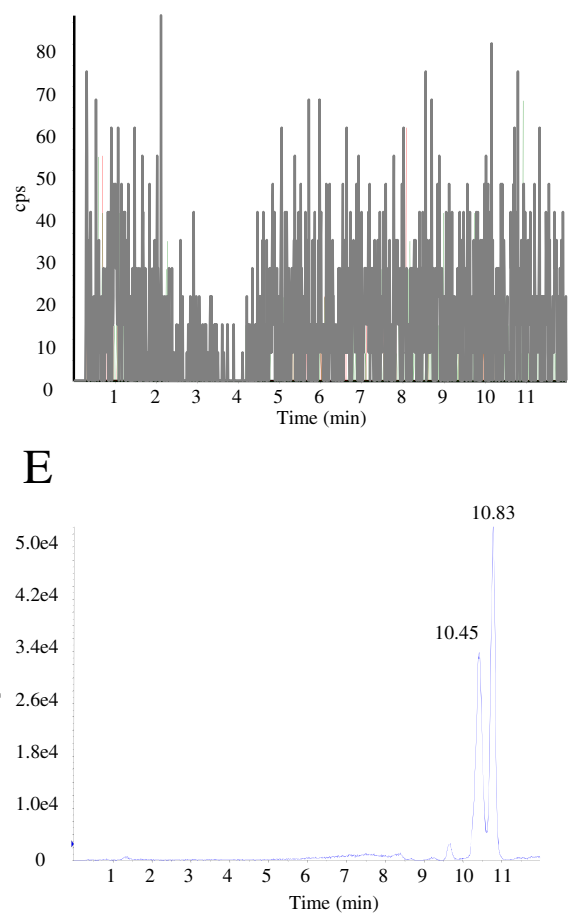

$\mathrm{B}$

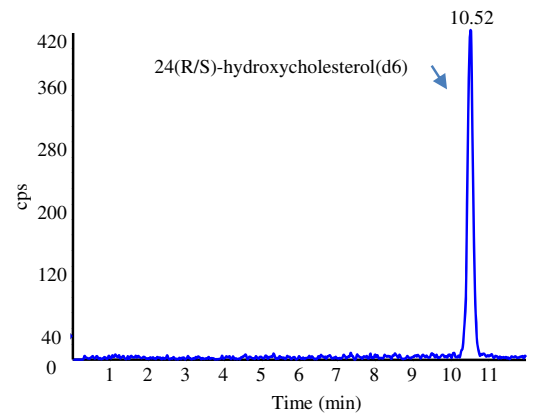

$\mathrm{D}$

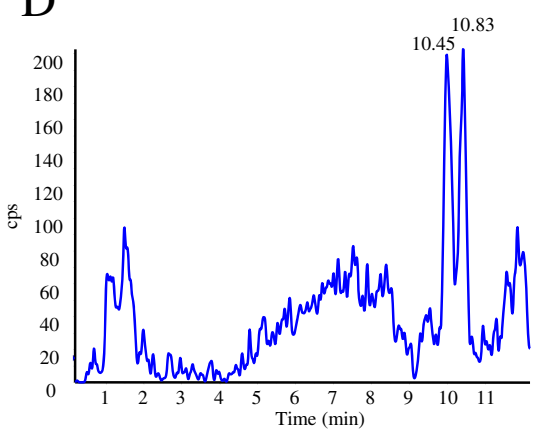

$\mathrm{F}$

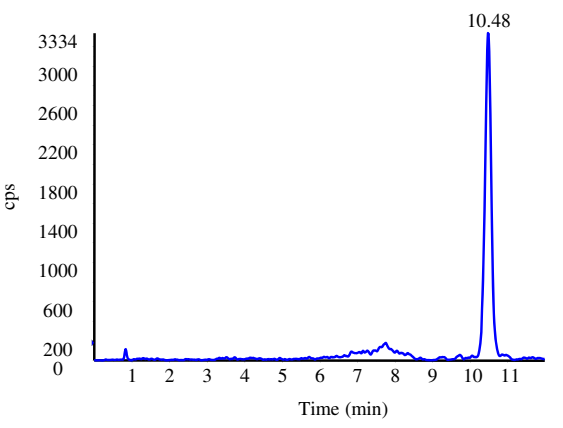

Figure 3 Chromatograms for 24S-hydroxycholesterol and 27-hydroxycholesterol. LC/MS/MS chromatograms for A) 24S-hydroxycholesterol and 27-hydroxycholesterol and B) 24(R/S)-hydroxycholesterol (d6). Base line chromatogram for C) methanol. D) Chromatogram for 24S-hydroxycholesterol (10.45) and 27-hydroxycholesterol (10.83) extracted from serum. E) Chromatogram for 24S-hydroxycholesterol and 27-hydroxycholesterols spiked serum sample. F) Chromatogram of 24(R/S)-hydroxycholesterol (d6) added into and extracted from serum sample. 
27-hydroxycholesterol were normalized to the peak area for the internal standard 24(R/S)-hydroxycholesterol (d6). The recovery of $24 S$-hydroxycholesterol was $59.1 \% \pm 6.99$, and recovery of 27 -hydroxycholesterol was $55.9 \% \pm 4.77$. The inter-day coefficient of variation for 24S-hydroxycholesterol was $8.9 \%$ and for 27 -hydrosxycholesterol was $3.9 \%$. Intraday coefficient of variations for 24S-hydroxycholesterol was $11.8 \%$, and for 27 -hydrosxycholesterol was $1.9 \%$. Accuracy for 24S-hydroxycholesterol and 27-hydroxycholesterol were between 91 to $118.2 \%$ (CVs for 50 and $100 \mathrm{ng}$ doses of 24S-hydroxycholesterol and 27-hydrosxycholesterol are shown in Table 2).

\section{Linearity, limits of detection and quantification}

Defined amounts of both 24S-hydroxycholesterol and 27-hydroxycholesterol standards (10, 50, 100, 500, $1000 \mathrm{ng} /$ $\mathrm{ml}$ ) were added to control serum samples prior to extraction. Standard curves were plotted as the ratio of the peak areas for 24S-hydroxycholesterol or 27-hydroxycholesterol to the peak area of the internal standard 24(R/S)-hydroxycholesterol (d6). Least-squares regression analysis for 24S-hydroxycholesterol and 27-hydroxycholesterol standard curves demonstrated linearity in the range of $10-$ $1000 \mathrm{ng} / \mathrm{ml}$ with a correlation coefficient of $\mathrm{r} 2$ for $24 \mathrm{~S}$ hydroxycholesterol $0.9979 \pm 0.0018$ and $0.9940 \pm 0.0018$ for 27-hydroxycholesterol (Table 3, Figure 4A). The limit of detection was calculated using the signal to noise ratio. The lower detection limits for 24S-hydroxycholesterol and 27-hydroxycholesterol were nearly identical at 248 fmoles on the column. We then calculated the concentration of free 24(S)-hydroxycholeserol and 27-hydroxycholesterol in our human serum samples. The average serum concentrations were $12.3 \pm 4.79 \mathrm{ng} / \mathrm{ml}$ for 24(s)-hydroxycholesterol and $17.7 \pm 8.5 \mathrm{ng} / \mathrm{ml}$ for 27-hydroxycholesterol (Figure 4).

\section{Discussion}

The goal of this study was to develop an efficient and rapid extraction protocol for LC/ESI/MS/MS-based detection and quantification of free 24S-hydroxycholesterol and 27hydroxycholesterol from human serum. For clinical studies, and for the potential use of these hydroxysterols as surrogate markers, it is important that sample analysis be rapid and cost effective. Here we present a simple, inexpensive, and rapid protocol for the extraction of 24S-hydroxycholesterol and 27-hydroxycholesterol from human serum. In addition, the simplicity of the extraction method increases data reproducibility by decreasing variability of product yield. This low cost and rapid sample preparation coupled with the high sensitivity of LC/MS/ MS instruments and accurate quantification by MRM make this a potentially powerful approach for the highthroughput quantification of hydroxycholesterol species in clinical and experimental samples.

This extraction method does not use saponification and therefore measures free hydroxycholesterols. This is an important consideration since free hydroxycholesterols are

Table 2 Precision and accuracy of hydroxycholesterols

\begin{tabular}{|c|c|c|c|c|}
\hline \multirow[t]{2}{*}{ Concentration (ng/ml) } & \multirow[t]{2}{*}{$\mathrm{n}$} & \multirow[t]{2}{*}{ Variables } & \multicolumn{2}{|l|}{ hydroxycholesterols } \\
\hline & & & 24S-hydroxycholesterol & 27-hydroxycholesterol \\
\hline & & & a. Inter-day analysis & \\
\hline \multirow[t]{4}{*}{50} & 5 & Mean (ng/ml) & 50.7 & 56.9 \\
\hline & & $\mathrm{SD}(\mathrm{ng} / \mathrm{ml})$ & 4.5 & 2.2 \\
\hline & & CV (\%) & 8.9 & 3.9 \\
\hline & & Accuracy (\%) & 101.4 & 113.6 \\
\hline \multirow[t]{5}{*}{100} & 5 & Mean (ng/ml) & 91.0 & 97.5 \\
\hline & & $\mathrm{SD}(\mu \mathrm{g} / \mathrm{ml})$ & 4.7 & 8.5 \\
\hline & & CV (\%) & 5.1 & 8.7 \\
\hline & & Accuracy (\%) & 91.0 & 97.5 \\
\hline & & & b. Intra-day analysis & \\
\hline \multirow[t]{4}{*}{50} & 5 & Mean (ng/ml) & 49.4 & 59.0 \\
\hline & & $\mathrm{SD}(\mathrm{ng} / \mathrm{ml})$ & 5.8 & 0.9 \\
\hline & & CV (\%) & 11.8 & 1.6 \\
\hline & & Accuracy (\%) & 98.8 & 118.2 \\
\hline \multirow[t]{4}{*}{100} & 5 & Mean $(\mu \mathrm{g} / \mathrm{ml})$ & 98.0 & 94.9 \\
\hline & & $\mathrm{SD}(\mathrm{ng} / \mathrm{ml})$ & 3.3 & 4.1 \\
\hline & & CV (\%) & 3.4 & 4.3 \\
\hline & & Accuracy (\%) & 98.0 & 94.9 \\
\hline
\end{tabular}


Table 3 Linearity calculated by regression analysis from standard curves of hydroxycholesterols

\begin{tabular}{|c|c|c|c|c|c|}
\hline \multirow[t]{3}{*}{ Analytes } & \multicolumn{4}{|c|}{${ }^{\text {a }}$ Regression analysis } & \multirow{3}{*}{$\begin{array}{l}\text { Correlation } \\
\text { coefficient } \\
\text { (R) }\end{array}$} \\
\hline & \multicolumn{2}{|l|}{ Slope } & \multicolumn{2}{|c|}{ Intercept } & \\
\hline & Mean & SD & Mean & SD & \\
\hline 24S-hydroxycholesterol & 0.3936 & 0.0988 & 0.0031 & 0.0018 & 0.9979 \\
\hline 27-hydroxycholesterol & 0.2948 & 0.0150 & 0.0127 & 0.0018 & 0.9940 \\
\hline
\end{tabular}

the most biologically active form of these sterols [40,41]. In our healthy human volunteers, serum concentrations ranged from 4 to $21 \mathrm{ng} / \mathrm{ml}$ for $24 \mathrm{~S}$-hydroxycholesterol and 4 to $29 \mathrm{ng} / \mathrm{ml}$ for 27 -hydroxycholesterol. These ranges are considerably lower than previously reported levels of total hydroxycholesterol in human serum that range from 60 to $83 \mathrm{ng} / \mathrm{ml}$ for $24 S$-hydroxycholesterol and 120 to $159 \mathrm{ng} / \mathrm{ml}$ for 27-hydroxycholesterol [18,24,42,43]. These data are consistent with findings that suggest more than $80 \%$ of 24 S-hydroxycholesterol and 27-hydroxychoelsterol are maintained in an esterfied state [17].

Since this is the first report of this extraction method, it is not possible to determine if measuring free hydroxycholesterols has a diagnostic or experimental advantage over measuring total hydroxycholesterols. In this study we analyzed a small number of samples to validate the method and did not compare to a disease state. However, we have recently used this method to quantitatively measure levels of free 24S-hydroxycholesterol and 27-hydroxycholesterol in serum of subjects who later developed cognitive impairment, and found that increased levels of free 24Shydroxycholesterol and the 24S-hydroxycholesterol/total cholesterol ratio were associated with greater risk of impairment on tasks that assess psychomotor speed and executive functioning, while higher levels of free 27hydroxycholesterol and the 27-hydroxycholesterol/total cholesterol ratio were associated with greater risk of delayed memory impairment. These data were qualitatively different from previous reports that measured total serum levels of these hydroxysterols. For example, total 27-hydroxycholesterol to total cholesterol ratio was associated with a faster decline of immediate memory recall over six years of follow-up [44]. Although, a second reported study did not find an association between total serum 24hydroxycholesterol or total 27-hydroxycholesterol and cognitive performance [45], this study measured total hydroxysterols. To date, only a single study has directly compared free to total levels of $24 S$-hydroxycholesterol and 27-hydroxycholesterol in serum. In this study it was reported that $80 \%$ of $24 \mathrm{~S}$-hydroxycholesterol and $85 \%$ of 27-hydroxycholesterol is esterfied in healthy volunteers. Males had higher levels of total 27-hydroxycholesterol compared to females. They found no other demographic or age-related differences in total 24S-hydroxycholesterol or 27-hydroxychoelsterol, and did not determine if there were age- or disease-related differences in free vs. esterfied hydroxycholesterols. Since it is the free forms of these hydroxysterols that have biological activity, and free forms are less than $20 \%$ of total hydroxysterols, it is possible that measuring total $24 S$-hydroxycholesterol and 27-hydroxycholesterol could mask a biological or diseaseassociated effect. These findings suggest that there may be important differences in free vs. total $24 S$ hydroxycholesterol and 27-hydroxycholesterols in relation to sex, age and neurodegenerative conditions that merit further study.

The ability to economically and efficiently measure $24 \mathrm{~S}$ hydroxycholesterol and 27-hydroxycholesterol in serum may also be useful as surrogate measures for the effectiveness of chemotherapeutics. The approximate cost per sample for this rapid extraction method is $\$ 3.00$. Saponification with solid phase extraction increases the approximate cost $\$ 18.00 /$ sample. These costs are for sample processing and do no include mass spectrometry time that is equal for

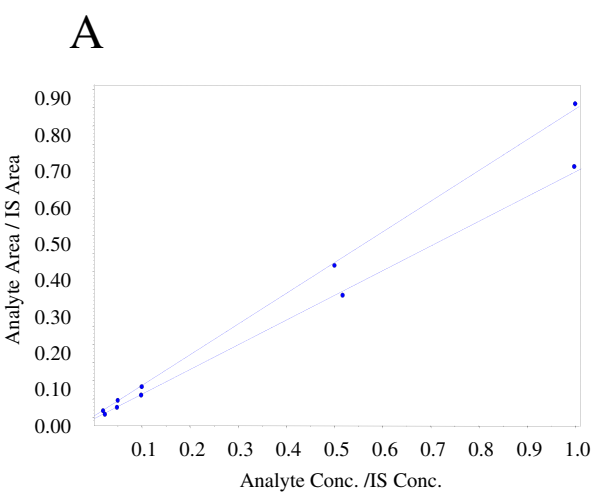

\section{B}

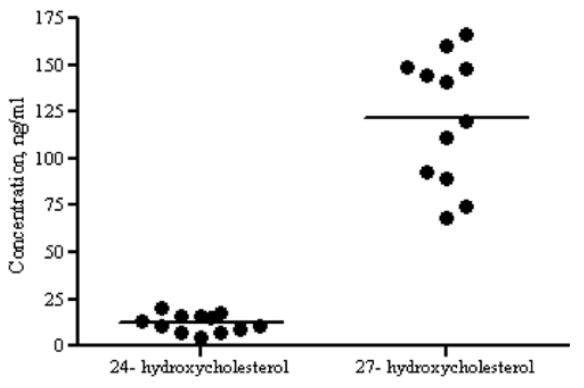

Figure 4 Quantification of free 24S-hydroxycholesterol and 27-hydroxycholesterol from normal human serum. A) Standard curves and B) quantities of free 24S-hydroxycholesterol and 27-hydroxycholesterol extracted from serum of healthy volunteers. 
both methods. Likewise sample run times are $12 \mathrm{~min} / \mathrm{sam}$ ple regardless of the extraction method. A number of sterol modifying agents are being tested as potential therapeutics for neurodegenerative disease [46-52], and it is possible that serum measures of 24S-hydroxycholesterol and 27-hydroxycholesterol may have utility as rapid and inexpensive surrogate markers to efficiently determine the effectiveness of therapeutics.

\section{Conclusion}

Serum measurements of these biologically active hydroxycholesterols may be useful surrogate measures for brain health in a variety of neurodegenerative conditions.

\section{Methods}

\section{Chemicals and equipment}

All solvents and chemicals were HPLC grade. Methanol $(\mathrm{CH} 3 \mathrm{OH})$, ethanol $(\mathrm{C} 2 \mathrm{H} 5 \mathrm{OH})$ and diethyl ether $(\mathrm{CH} 3-$ $\mathrm{CH} 2-\mathrm{O}-\mathrm{CH} 2-\mathrm{CH} 3)$ were purchased from Fisher Scientific (USA), ammonium formate (HCOONH4) and formic acid $(\mathrm{HCOOH})$ were purchased from Sigma Aldrich (St. Louis, MO). 24S-hydroxycholesterol and 27-hydroxycholesterol were purchased form Research Plus Inc. (Barnegat, NJ). Internal standard 24(R/S)-hydroxycholesterol (d6) [cholest5-ene-3 $\beta, 24(\mathrm{R} / \mathrm{S})$-diol (d6)] was purchased from Avanti Polar Lipids (Alabaster, AL). Glass vials were purchased from Agilent Technologies, Inc. (Santa Clara, CA). Isotemp vacuum oven was purchased from Fisher Scientific (Model 285A, Pittsburgh, PA). Borosilicate-coated glass tubes and pipettes were used to reduce adhesion of sterols to plastic and glassware (Fisher Scientific, Pittsburgh, PA).

\section{Serum samples}

Human serum was obtained from 12 healthy volunteers (5 males and 7 females) age 25-36 years at the Johns Hopkins University School of Medicine. Approximately $8 \mathrm{ml}$ (human) blood was collected into BD P100 tubes Sodium heparin (Beckton Dickenson, Franklin Lakes, $\mathrm{NJ})$. Tubes were inverted $8-10$ times to mix the protease inhibitors and anticoagulent with the blood sample then placed onto ice. Blood was then centrifuged at $2000 \mathrm{~g}$ at $4^{\circ} \mathrm{C}$ for $15 \mathrm{~min}$. Serum was aliquoted and transferred into cryovials for storage at $-80^{\circ} \mathrm{C}$ until use. All samples underwent a single freeze-thaw cycle before use.

\section{Extraction of 24S-hydroxycholesterol and 27- hydroxycholesterol}

We developed a single step direct extraction method for both 24S-hydroxycholesterol and 27-hydroxycholesterol. For extraction, $0.5 \mathrm{ml}$ of Serum was transferred into a glass tube and $5 \mu \mathrm{l}$ of $24(\mathrm{R} / \mathrm{S})$-hydroxycholesterol (d6) (internal standard) from $100 \mu \mathrm{g} / \mathrm{ml}$ stock was added, followed by $3 \mathrm{ml}$ of pure ethanol and the mixture vortexed. Diethyl ether $(4 \mathrm{ml})$ was then were added and the mixture vortexed and centrifuged at 4,000 $\mathrm{g}$ for 10 minutes. The supernatant was separated and the residue was re-extracted using the same volumes of solvents as was used in the initial extraction. Supernatants were mixed together, and dried under a stream of nitrogen or in a vacuum oven at $30^{\circ} \mathrm{C}$ (we did not observe any qualitative or quantitative differences when samples were dried under nitrogen compared with a vacuum oven). Dried extracts were re-suspended into $100 \mu \mathrm{l}$ of methanol, vortexed, centrifuged and transferred to an autosampler vial insert where it was maintained at $4^{\circ} \mathrm{C}$. Samples were injected into the HPLC using an Agilent 1100 series autosampler (Agilent Technologies, Inc., Santa Clara CA, United States).

\section{Quantification of hydroxycholesterols by LC/ESI/MS/MS using multiple reaction monitoring (MRM)}

Sample analysis was performed using triple quadrupole LC/ ESI/MS/MS API3000 mass Spectrometer (Applied Biosystems, Thornhill, Ontario, Canada). The HPLC consisted of an Agilent 1100 series with a quaternary pump, degasser, autosampler and thermostatted column. The column was a Luna $5 \mu \mathrm{M} \mathrm{C18} 100 \AA 100 \times 2 \mathrm{~mm}$ coupled to a guard column with packing material identical to the column (Phenomenex, Torrance, CA). Chromatography was conducted in gradient elution mode using solvent $\mathrm{A}$ (water with $5 \mathrm{mM}$ ammonium formate) and solvent $\mathrm{B}$ (pure methanol with $5 \mathrm{mM}$ ammonium formate) at flow rate of $0.3 \mathrm{ml} / \mathrm{min}$. Hydroxycholesterols were separated using the following gradient conditions: $0.0-0.3 \mathrm{~min}, 85 \% \mathrm{~B} ; 0.3$ - 9 min gradient to $100 \%$ B; 9-12 min 0\% B (Table 4). Injection volume of samples was $10 \mu \mathrm{l}$. Quantification was conducted by MRM using Analyst 1.4.2 software (Applied Biosystems).

Table 4 Gradient conditions for LC

\begin{tabular}{lllll}
\hline Step & Total time $(\mathbf{m i n})$ & Flow rate $(\boldsymbol{\mu l} / \mathbf{m i n})$ & Mobile phase $\mathbf{A}^{*}(\%)$ & Mobile phase $\mathbf{B}^{*}(\%)$ \\
\hline 0 & 0 & 300 & 100 & 0 \\
1 & 0.3 & 300 & 15 & 85 \\
2 & 9 & 300 & 0 & 100 \\
3 & 12 & 300 & 100 & 0 \\
\hline
\end{tabular}

${ }^{*} \mathrm{~A}$ : water with $5 \mathrm{mM}$ ammonium formate, B: pure methanol with $5 \mathrm{mM}$ ammonium formate. 


\section{Standards for quantitative analysis and correction of extraction efficiency}

Stock solutions for 24S-hydroxycholesterol, 27hydroxycholesterol, and 24(R/S)-hydroxycholesterol (d6) (internal standard) were prepared separately in $\mathrm{CH} 3 \mathrm{OH}$ to produce a concentration range of $10 \mathrm{ng} / \mathrm{ml}$ to $1000 \mathrm{ng} / \mathrm{ml}$. Samples were spiked with $1 \mu \mathrm{g} / \mathrm{ml} 24(\mathrm{R} /$ S)-hydroxycholesterol (d6) that was used as an internal control to correct for slight differences in ionization efficiency, chromatographic retention, fragmentation and molecular interactions between hydroxycholesterol species. Blank serum samples were used for background correction. Calibration curves were plotted using the peak area ratios of 24S-hydroxycholesterol or 27-hydroxycholesterol to 24(R/S)-hydroxycholesterol (d6). All stock solutions were stored at $-20^{\circ} \mathrm{C}$. Calibrations were conducted using least squares linear regression.

Standard protocol approvals, registrations, and patient consents The collection and use of human samples was approved by the IRB the Johns Hopkins University SOM and included written and informed consent for the use of Serum for research purposes.

Competing interests

The authors declare that they have no competing interests.

\section{Authors' contributions}

WRB developed the extraction and mass spectrometry methods, participated in the design of the study and helped draft the manuscript. NJH conceived of the study, and study design, sample collection, coordination, and was responsible for the final draft of the manuscript. All authors read and approved the final manuscript.

\section{Acknowledgements}

This research was supported by the National Institute of Health grants AG023471, MH077542 and AA017408 to NJH. The authors would like to thank Fang Yang and Lepakshi Sahni for expert technical assistance.

Received: 20 June 2014 Accepted: 17 December 2014

Published online: 24 December 2014

\section{References}

1. Brown AJ, Jessup W: Oxysterols and atherosclerosis. Atherosclerosis 1999, 142(1):1-28

2. Bjorkhem I, Andersson O, Diczfalusy U, Sevastik B, Xiu RJ, Duan C, Lund E: Atherosclerosis and sterol 27-hydroxylase: evidence for a role of this enzyme in elimination of cholesterol from human macrophages. Proc Natl Acad Sci U S A 1994, 91(18):8592-8596.

3. Brown MS, Goldstein JL: Suppression of 3-hydroxy-3-methylglutaryl coenzyme A reductase activity and inhibition of growth of human fibroblasts by 7-ketocholesterol. J Biol Chem 1974, 249(22):7306-7314.

4. Kandutsch AA, Chen HW, Shown EP: Binding of 25-hydroxycholesterol and cholesterol to different cytoplasmic proteins. Proc Natl Acad Sci U S A 1977, 74(6):2500-2503.

5. Danielsson H: Present Status of Research on Catabolism and Excretion of Cholesterol. Adv Lipid Res 1963, 1:335-385.

6. Bjorkhem I, Meaney S, Diczfalusy U: Oxysterols in human circulation: which role do they have? Curr Opin Lipidol 2002, 13(3):247-253.

7. Repa JJ, Mangelsdorf DJ: The role of orphan nuclear receptors in the regulation of cholesterol homeostasis. Annu Rev Cell Dev Biol 2000, 16:459-481.

8. Schroepfer GJ Jr: Oxysterols: modulators of cholesterol metabolism and other processes. Physiol Rev 2000, 80(1):361-554.
9. Ares MP, Porn-Ares MI, Thyberg J, Juntti-Berggren L, Berggren PO, Diczfalusy U, Kallin B, Bjorkhem I, Orrenius S, Nilsson J: Ca2+ channel blockers verapamil and nifedipine inhibit apoptosis induced by 25 -hydroxycholesterol in human aortic smooth muscle cells. J Lipid Res 1997, 38(10):2049-2061.

10. Gabbi C, Kim HJ, Hultenby K, Bouton D, Toresson G, Warner M, Gustafsson JA: Pancreatic exocrine insufficiency in LXRbeta-/- mice is associated with a reduction in aquaporin-1 expression. Proc Natl Acad Sci U S A 2008, 105(39):15052-15057.

11. Kolsch H, Ludwig M, Lutjohann D, Rao ML: Neurotoxicity of 24hydroxycholesterol, an important cholesterol elimination product of the brain, may be prevented by vitamin E and estradiol-17beta. J Neural Transm 2001, 108(4):475-488.

12. Kotti T, Head DD, McKenna CE, Russell DW: Biphasic requirement for geranylgeraniol in hippocampal long-term potentiation. Proc Natl Acad Sci U S A 2008, 105(32):11394-11399.

13. Lahoua Z, Astruc ME, Barjon JN, Michel F, de Crastes Paulet A: Mechanism of the activation of arachidonic acid release by oxysterols in NRK $49 \mathrm{~F}$ cells: role of calcium. Cell Signal 1989, 1(6):569-576.

14. Lee CS, Park WJ, Han ES, Bang H: Differential modulation of 7ketocholesterol toxicity against PC12 cells by calmodulin antagonists and Ca2+ channel blockers. Neurochem Res 2007, 32(1):87-98.

15. Sacchetti P, Sousa KM, Hall AC, Liste I, Steffensen KR, Theofilopoulos S, Parish CL, Hazenberg C, Richter LA, Hovatta O, Gustafsson JA, Arenas E: Liver $\mathrm{X}$ receptors and oxysterols promote ventral midbrain neurogenesis in vivo and in human embryonic stem cells. Cell Stem Cell 2009, 5(4):409-419.

16. Trousson A, Bernard S, Petit PX, Liere P, Pianos A, El Hadri K, Lobaccaro JM Ghandour MS, Raymondjean M, Schumacher M, Massaad C: 25hydroxycholesterol provokes oligodendrocyte cell line apoptosis and stimulates the secreted phospholipase A2 type IIA via LXR beta and PXR. J Neurochem 2009, 109(4):945-958.

17. Burkard I, von Eckardstein A, Waeber G, Vollenweider P, Rentsch KM: Lipoprotein distribution and biological variation of 24S- and 27-hydroxycholesterol in healthy volunteers. Atherosclerosis 2007, 194(1):71-78.

18. Dzeletovic S, Breuer O, Lund E, Diczfalusy U: Determination of cholesterol oxidation products in human plasma by isotope dilution-mass spectrometry. Anal Biochem 1995, 225(1):73-80.

19. Ramirez DM, Andersson S, Russell DW: Neuronal expression and subcellular localization of cholesterol 24-hydroxylase in the mouse brain. J Comp Neurol 2008, 507(5):1676-1693.

20. Heverin M, Meaney S, Lutjohann D, Diczfalusy U, Wahren J, Bjorkhem I: Crossing the barrier: net flux of 27-hydroxycholesterol into the human brain. J Lipid Res 2005, 46(5):1047-1052.

21. Koschack J, Lutjohann D, Schmidt-Samoa C, Irle E: Serum 24S hydroxycholesterol and hippocampal size in middle-aged normal individuals. Neurobiol Aging 2009, 30(6):898-902.

22. Leoni V, Mariotti C, Tabrizi SJ, Valenza M, Wild EJ, Henley SM, Hobbs NZ, Mandelli ML, Grisoli M, Bjorkhem I, Cattaneo E, Di Donato S: Plasma 24S-hydroxycholesterol and caudate MRI in pre-manifest and early Huntington's disease. Brain 2008, 131(Pt 11):2851-2859.

23. Lutjohann D, Bjorkhem I, Locatelli S, Dame C, Schmolling J, von Bergmann K, Fahnenstich $\mathrm{H}$ : Cholesterol dynamics in the foetal and neonatal brain as reflected by circulatory levels of 24S-hydroxycholesterol. Acta Paediatr 2001, 90(6):652-657.

24. Lutjohann D, Papassotiropoulos A, Bjorkhem I, Locatelli S, Bagli M, Oehring RD, Schlegel U, Jessen F, Rao ML, von Bergmann K, Heun R: Plasma 24S-hydroxycholesterol (cerebrosterol) is increased in Alzheimer and vascular demented patients. J Lipid Res 2000, 41(2):195-198.

25. Meng LJ, Griffiths WJ, Nazer H, Yang Y, Sjovall J: High levels of (24S)-24hydroxycholesterol 3-sulfate, 24-glucuronide in the serum and urine of children with severe cholestatic liver disease. J Lipid Res 1997 38(5):926-934

26. Papassotiropoulos A, Lutjohann D, Bagli M, Locatelli S, Jessen F, Buschfort $R$, Ptok U, Bjorkhem I, von Bergmann K, Heun R: 24S-hydroxycholesterol in cerebrospinal fluid is elevated in early stages of dementia. J Psychiatr Res 2002, 36(1):27-32.

27. Teunissen CE, Floris S, Sonke M, Dijkstra CD, De Vries HE, Lutjohann D: 24S-hydroxycholesterol in relation to disease manifestations of acute experimental autoimmune encephalomyelitis. J Neurosci Res 2007, 85(7):1499-1505. 
28. Andersson S, Davis DL, Dahlback H, Jornvall H, Russell DW: Cloning, structure, and expression of the mitochondrial cytochrome P-450 sterol 26-hydroxylase, a bile acid biosynthetic enzyme. J Biol Chem 1989, 264(14):8222-8229.

29. Cali JJ, Russell DW: Characterization of human sterol 27-hydroxylase. A mitochondrial cytochrome P-450 that catalyzes multiple oxidation reaction in bile acid biosynthesis. J Biol Chem 1991, 266(12):7774-7778.

30. Javitt NB: 25R,26-Hydroxycholesterol revisited: synthesis, metabolism, and biologic roles. J Lipid Res 2002, 43(5):665-670.

31. Esterman AL, Baum H, Javitt NB, Darlington GJ: 26-hydroxycholesterol: regulation of hydroxymethylglutaryl-CoA reductase activity in Chinese hamster ovary cell culture. J Lipid Res 1983, 24(10):1304-1309.

32. Javitt NB: Bile acid synthesis from cholesterol: regulatory and auxiliary pathways. Faseb J 1994, 8(15):1308-1311.

33. Reiss AB, Martin KO, Javitt NB, Martin DW, Grossi EA, Galloway AC: Sterol 27-hydroxylase: high levels of activity in vascular endothelium. $J$ Lipid Res 1994, 35(6):1026-1030.

34. Russell DW: Oxysterol biosynthetic enzymes. Biochim Biophys Acta 2000, 1529(1-3):126-135.

35. Breuer O, Bjorkhem I: Simultaneous quantification of several cholesterol autoxidation and monohydroxylation products by isotope-dilution mass spectrometry. Steroids 1990, 55(4):185-192.

36. Sevanian A, Seraglia R, Traldi P, Rossato P, Ursini F, Hodis H: Analysis of plasma cholesterol oxidation products using gas- and high-performance liquid chromatography/mass spectrometry. Free Radic Biol Med 1994, 17(5):397-409.

37. Csallany AS, Kindom SE, Addis PB, Lee JH: HPLC method for quantitation of cholesterol and four of its major oxidation products in muscle and liver tissues. Lipids 1989, 24(7):645-651.

38. Zhang Z, Li D, Blanchard DE, Lear SR, Erickson SK, Spencer TA: Key regulatory oxysterols in liver: analysis as delta4-3-ketone derivatives by HPLC and response to physiological perturbations. J Lipid Res 2001, 42(4):649-658

39. Griffiths WJ, Wang Y, Alvelius G, Liu S, Bodin K, Sjovall J: Analysis of oxysterols by electrospray tandem mass spectrometry. J Am Soc Mass Spectrom 2006, 17(3):341-362.

40. Meaney S, Hassan M, Sakinis A, Lutjohann D, von Bergmann K, Wennmalm A, Diczfalusy U, Bjorkhem I: Evidence that the major oxysterols in human circulation originate from distinct pools of cholesterol: a stable isotope study. J Lipid Res 2001, 42(1):70-78.

41. Meaney S, Lutjohann D, Diczfalusy U, Bjorkhem I: Formation of oxysterols from different pools of cholesterol as studied by stable isotope technique: cerebral origin of most circulating 24S-hydroxycholesterol in rats, but not in mice. Biochim Biophys Acta 2000, 1486(2-3):293-298.

42. Babiker A, and Diczfalusy: Transport of side-chain oxidized oxysterols in the human circulation. Biochem Biophysics Acta 1998(1392):333-339.

43. Burkard I, Rentsch KM, von Eckardstein A: Determination of 24S- and 27-hydroxycholesterol in plasma by high-performance liquid chromatography-mass spectrometry. J Lipid Res 2004, 45(4):776-781.

44. van den Kommer TN, Dik MG, Comijs HC, Fassbender K, Lutjohann D, Jonker C: Total cholesterol and oxysterols: early markers for cognitive decline in elderly? Neurobiol Aging 2009, 30(4):534-545.

45. Teunissen CE, De Vente J, von Bergmann K, Bosma H, van Boxtel MP, De Bruijn C, Jolles J, Steinbusch HW, Lutjohann D: Serum cholesterol, precursors and metabolites and cognitive performance in an aging population. Neurobiol Aging 2003, 24(1):147-155.

46. Locatelli S, Lutjohann D, Schmidt HH, Otto C, Beisiegel U, von Bergmann K: Reduction of plasma 24S-hydroxycholesterol (cerebrosterol) levels using high-dosage simvastatin in patients with hypercholesterolemia: evidence that simvastatin affects cholesterol metabolism in the human brain. Arch Neurol 2002, 59(2):213-216.

47. Davis W Jr: The cholesterol transport inhibitor U18666a regulates amyloid precursor protein metabolism and trafficking in N2aAPP "Swedish" cells. Current Alzheimer Res 2008, 5(5):448-456.

48. Davis HR Jr, Murgolo NJ, Graziano MP: Simvastatin with or without ezetimibe in familial hypercholesterolemia. N Engl J Med 2008 359(5):531. author reply 532-533.

49. Whitfield JF: The road to LOAD: late-onset Alzheimer's disease and a possible way to block it. Expert Opin Ther Targets 2007, 11(10):1257-1260.

50. Vaya J, Schipper HM: Oxysterols, cholesterol homeostasis, and Alzheimer disease. J Neurochem 2007, 102(6):1727-1737.
51. Papassotiropoulos A, Wollmer MA, Tsolaki M, Brunner F, Molyva D, Lutjohann D, Nitsch RM, Hock C: A cluster of cholesterol-related genes confers susceptibility for Alzheimer's disease. J Clin Psychiatry 2005, 66(7):940-947

52. Chang TY, Chang CC, Bryleva E, Rogers MA, Murphy SR: Neuronal cholesterol esterification by ACAT1 in Alzheimer's disease. IUBMB Life.

\section{Submit your next manuscript to BioMed Central and take full advantage of:}

- Convenient online submission

- Thorough peer review

- No space constraints or color figure charges

- Immediate publication on acceptance

- Inclusion in PubMed, CAS, Scopus and Google Scholar

- Research which is freely available for redistribution

Submit your manuscript at www.biomedcentral.com/submit
C BioMed Central 